\title{
Study on the Beauty of Artistic Conception in Chinese Style Illustrations
}

\author{
Liping Mao \\ Luoyang Normal University \\ Luoyang, China
}

\begin{abstract}
Chinese style illustration is a unique form of visual expression, it has historical, aesthetic, practical, national, and creative characteristics. In today's world where digital technology is widely used, ancient style illustrations draw the charm of artistic beauty from traditional Chinese culture and painting art. It is both a heritage of Chinese traditional culture and also an excellent blend of materials for illustration art.
\end{abstract}

Keywords-Chinese style; illustration; beauty of artistic conception

\section{INTRODUCTION}

Illustrations are derived from Latin, meaning "illumination", which means that the illustrations in books can make text ideas clearer. Today, in the digital world, illustrations are no longer just pictures in the book to assist in the interpretation of text, but are widely used in commercial and pop culture fields such as advertising, books, animation games, packaging, etc. through visual communication.

Chinese style refers to the style of China. In recent years, with the popularity of Japanese and Korean comics, ancient costume TV series, time-travel novels and ghost and god novels, it has attracted a large number of illustrators to follow Chinese style illustrations. The fusion of traditional Chinese elements and illustrations has given a strong Chinese style to the contemporary illustration art. The theme and content involve Chinese history and humanities. In terms of performance techniques, it draws on the traditional methods of line drawing and ink painting. In terms of aesthetics, it is in harmony with traditional Chinese aesthetics, pursuing subtle, elegant, and aesthetic styles, and the supreme realm of artistic beauty.

\section{AESTHETIC SOURCES OF THE BEAUTY OF ARTISTIC CONCEPTION}

\section{A. The Core of Chinese Traditional Culture Is the}

Harmonious Value of "Harmony Between Human and

Nature", Which Respects Nature and Humanism

Under the guidance of such thinking, Chinese traditional poetry, calligraphy and painting all pay great attention to artistic conception. Artists' image creation is not only an objective copy of the image, but also an expression of the painter's perception of themselves and nature through the combination of images and meaning. After the artistic processing, it can express feelings in the scene and the scene also can be the carrier of feelings. In the highly integrated love and scenery, the artistic realm reflected in the mutual care of human and nature is the artistic conception. The ancient literati and writers realized the relationship between man and nature from the paintings and calligraphy, explored the rules of entering and exiting life, and admired the poetic imagination. Artistic conception gives them a space for galloping imagination and fulfills their pursuit of nihilism. To them, artistic conception is the life and soul of art. Therefore, artistic conception is regarded as the highest state of traditional Chinese painting, and pursuit of artistic conception is an important part of traditional Chinese aesthetic thought.

\section{B. The Traditional Culture of Confucianism, Buddhism and Taoism Has a Profound Influence on Chinese Traditional Aesthetics}

Confucianism began to influence Chinese culture in the late Spring and Autumn period, and it gradually became mainstream though in the Han Dynasty. With the development of the times, Buddhist thought has gradually penetrated into our traditional culture in the Eastern Han Dynasty. The Taoism dominated by Lao Zhuang thoughts interact with Confucian culture, and integrate the Buddhist ideological culture and the fairy system, which makes the traditional Chinese culture have a profound accumulation of Confucianism, Buddhism and Taoism, which affects our country's aesthetics for thousands of years. In the Buddhist mural art represented by Mogao Grottoes, there are a large number of exquisite images of Confucianism, Buddhism, Taoism three religious combined together. Their shapes are vivid and lively, the lines are elegant and beautiful, and the colors are rich and graceful. Although they have been through thousands of years, they have not lost their splendid and noble realm. From them we that see the immortal breeze of Taoism and the meticulous rigor of Confucianism have influenced the artist's creation, raising the traditional aesthetic state of art to the extreme and perfect height.

\section{China's Traditional Art of Calligraphy and Painting Is Fascinating}

Whether it is brushwork or freehand, flowers, birds, or landscapes, it pursues elegant style and vivid charm. The writing brush movement of writing tools is agile and changeable, which is rich in formal beauty, and has dialectical meaning of Rou Kegang. Pen, ink and paper work together 
perfectly express the artistic conception of traditional painting. The weight of pen writing brings a huge difference in the thickness of the lines, the gradual softness of the water and the pen tip dipped in ink, and the different effects of different painting paper materials. The artistic charm emanating from the unique expression of traditional Chinese calligraphy and painting creates a fascinating artistic conception.

\section{THE PERFORMANCE OF ARTISTIC BEAUTY}

\section{A. Ethereal Beauty}

Traditional painting art pays attention to the beauty of artistic conception that is extraordinary and subtle. The painting consciousness is the artistic concept of freehand drawing, it focus on spirituality expressing, quietness to contain everything and image creation as the symbol, express the scenes, feelings and emotions through ethereal beauty of artistic concept. The main creative method is ink painting, which is good at expressing scenes with different shades of ink color, and uses just right blank-leaving to enhance people's imagination. The ethereal beauty is also expressed in the rich meaning conveyed by the changing lines, which lead people to endless aftertastes.

\section{B. Poetic Beauty}

Since ancient times, there has been a saying that calligraphy and painting are of the same origin. The integration of poetry and painting is the highest ideal pursued by painters and the highest state of Chinese painting creation. The poetic beauty of the artistic conception of Chinese painting is a few strokes to express infinite feelings, and the beauty is a few ink marks trigger boundless association. It is this kind of poetic beauty that makes traditional Chinese paintings have extra rhyme, feelings outside the painting. For example, in the Song Dynasty Ma Yuan 's "Fishing on the cold river", the painting has a large amount of blank-leaving, only a few strokes in the center outlined a flat boat, a fisherman sat on it and looked at the fish in the river. The wave rippling under the boat, distant mountains are blurring. This mood is reminiscent of the poem "Jiang Xue" by Liu Zongyuan of the Tang Dynasty: "Qian shan niao fei jue, wan jing ren zong mie. Gu zhou suo li wong, du diao han jiang xue." (All birds are vanished in hills, as well as human tracks. But only one man in cape and hat of bamboo, fishing in a solitary skiff on a snowy river.) It can be described as "there is painting in poetry, there is poetry in painting". The poetic beauty of the artistic conception of traditional Chinese painting shows the similarity between various arts. Poetic spirit deepens the connotation of artistic conception of painting, while painting solidifies the poet's interpretation of poetry, the complement of poetry and painting makes the artistic conception more profound.

\section{Humanistic Beauty}

Chinese painters of all ages were influenced by the cultural thoughts of the Chinese nation for thousands of years while receiving the influence of art, especially Laozi's inaction and Zhuangzi's carefree thoughts had a profound impact on them. In addition, the benevolence, righteousness, propriety, wisdom and the consciousness of The wise are happy with water, the benevolent are happy with mountain, which advocated by Confucianism are deeply embedded in their views. They wander in and out of the mountains and rivers, ponder between the universe and nature, and the thick humanistic atmosphere becomes the basis of their observation of the landscape. They cultivate ambitions with moral and observe objects with emotions, and they put their feelings in the mountains and rivers, and express their emotions in the clouds. In their paintings, the inanimate mountains and trees seem to know to abide by the rules of etiquette, and they also understand the joys and sorrows of the world.

\section{THE VALUE OF INCORPORATING ARTISTIC BEAUTY INTO ILLUSTRATIONS}

The role of illustrations is becoming more and more important in our lives. Incorporating Chinese elements into illustrations can add artistic beauty to illustrations and make illustrations with more Chinese charm. Chinese charm is the most representative part of China's national culture in the history of 5,000 years, and the influence of traditional culture on modern illustration art should be huge and profound. During the refinement of thousand years of Chinese history, numerous cultural relics have been left. They reflect the high achievements of traditional Chinese culture and enjoy a high reputation in the world. Chinese traditional art and culture is deeply influenced by Confucianism, Buddhism, Taoism and other ideas, and has the characteristics of great national integration. It is manifested in the art as a modest, symmetrical aesthetic view, which pays attention to profound, blank-leaving and change of virtual and reality. The techniques often used in artistic creation are yin and yang, rigid and flexible, dynamic and static, real and virtual application, and they are used to express the aesthetic concept of tranquility, elegance, and subtle mood. Actively absorbing the essence of illustration creation is not only the inheritance of the Chinese tradition, but also can maintain our own national history and characteristics in the today's art globalization. The use of these ancient techniques and elements in contemporary art forms such as illustrations can also arouse people's attention and love for traditional Chinese cultural elements, so that our outstanding cultural traditions will not gradually vanish, which is related to the cultural memory and cultural confidence of the nation.

In addition, the expression of artistic conception can enhance the competitiveness of works in commercial operations. Major animation companies in the world have recognized the value of Chinese charm in business, and have used clear Chinese elements in their animation works, such as classic characters, traditional cloud pattern, water pattern, red lantern, panda and other representative elements, which successfully attracted attention from all over the world, and received numerous praise. This shows that Chinese elements and Chinese charm have a world-renowned reputation for their unique visual charm and artistic conception.

The work of Chinese illustrator Ni Chuanjing is an example of the integration of Chinese elements into illustration and the beauty of artistic conception. Her works have both the beauty of appearance and the beauty of artistic conception. The composition and color especially emphasize the atmosphere of joy and peace, and the images in the picture are lively, dynamic, 
meaning prosperous country and peaceful people. Her works are elegant, gorgeous, graceful, and have a high degree of public recognition. This is very important in the era of internet and big data, it helps Chinese style to spread to the world through illustrations, and also enables the artistic conception in Chinese style illustrations is understood and recognized by the world.

\section{THE EXPRESSION OF ARTISTIC CONCEPTION OF CHINESE STYLE ILLUSTRATIONS}

\section{A. Traditional Hand-drawn Illustrations}

Traditional hand-drawn illustrations are the closest to traditional painting and the most rustic way of expression. Through traditional ink, paper, strokes, and color rendering, the artistic beauty of traditional art can be captured most closely and strongly. The emotion and temperature contained in the beauty of artistic conception are also slowly passed on in handdrawings, and traditional culture can subtly influence generations of illustrators.

Chinese style hand-drawn illustrations are good at using watercolor, color lead, color powder and other tools to express a fresh, gorgeous, rich and elegant emotional atmosphere. The coloring of the picture is full of changes and vividness. The main color of the picture is either cold or warm, and the auxiliary colors are subtle and euphemistic, with subtle layers, which bring a quiet and profound effect, or it draw on traditional Chinese auspicious colors such as red to convey the festive and warm emotional atmosphere. The use of unique Chinese colors such as turquoise, rouge, and cyan can enhance the ancient charm of the picture.

Lines are the most typical traits of traditional painting art. They are most frequently used in illustration art, with their most concise and individualized factors, lines not only shape the body in the picture, but also interpret the emotions of the work through the sense of dense, slender and forms. Focusing on the line, the power of the line is combined with the change of the line to express the characteristics of the shape and the interpenetrating relationship of the structure. The speed of the hand, the stop and strength of the pen, the straightness and depth of the line could create fluency, stagnation, and different rhythms and textures of the lines. And it can also produce different personality moods, coupled with the texture of the water color, expressing the variety of emotions and the beauty of artistic conception of the works.

The main feature of hand-drawn illustrations is the trace of hand-drawing. Chinese-style hand-drawn illustrations are mostly created with tools such as pigment for Chinese painting, brushes, watercolors, and colored lead. The picture with watercolor is permeated with the rough rustic feeling of paper and the mottled feeling of water stain. The works with watersoluble colored lead are filled with soft, delicate brushstrokes. Each tool brings its own magical effect to the illustration due to its unique texture and expressiveness.

\section{B. New Media}

Today, the world is informationalized and digitized, and the emerging new media are powerful. As long as the illustrator has a skilled hand-drawing background, combined with photography and camera technology, hand-drawing board, and computer software technology, the line language and ink of traditional Chinese painting can be perfectly combined with digital technology. The media technology is fast and efficient in deal with the changing rhythm and scene atmosphere creation. The powerful post-function of the software can also provide functions such as color adjustment and various special effects, making the illustration works more magnificent, and provide illustrators with more magical and innovative ideas, expressing the beauty of artistic concept with the times.

In 2004, "Strange Stories from a Chinese Studio Filling the Vacancy, Illusionary World", the work of illustrator Zhang Wang at the Asian Animation Exhibition, is an example of the perfect combination of digital technology and illustration art. In his works, from the whole to the details, every stroke and every line are impeccable, every start, running and finish of the stroke is round and smooth without losing tension. The picture is fresh, light, and hazy, the fox fairy created through refinement, exaggeration, and creation so that it has a classic and fantasy image. The fox fairy expressing charm with eyes and eyebrows, the skirt is elegant and light, with strong threedimensional and dynamic, as if her long sleeves can dance, he lips can sing, and she has a soul and though. The storyline makes the picture has the beauty of artistic conception.

\section{CONCLUSION}

The theme of Chinese style illustrations comes from people's perception and reproduction of ancient history, characters, and events. The organic combination of traditional art techniques in illustration creation can give illustrations a special soul and convey China's unique artistic conception. The relationship between Chinese style and illustration is complementary, which is also the basis for the common development of the two. Incorporating Chinese charm into illustrations and absorbing the artistic beauty of traditional paintings are the inheritance and development of traditional Chinese aesthetics. It can also promote the development of illustration art and improve the innovation level of Chinese style illustrations.

\section{REFERENCES}

[1] Wang Qiang. "Study on the image features and expressive language of hand-drawn illustrations" [D] Shanxi University. 2013: 34. (in Chinese)

[2] Gao Jing. "On the characteristics of Chinese style hand-drawn illustration " [J] Design.2017. (13): 76-77. (in Chinese)

[3] Li Jing.Tang Fei. "How to integrate illustration design into traditional Chinese elements" [J]. Ability and Wisdom .2015 (5). (in Chinese) 